\title{
Prenatal Diagnosis of X-Linked Centronuclear Myopathy by Linkage Analysis
}

\author{
SABINA LIECHTI-GALLATI, GERHARD WOLFF, UWE-PETER KETELSEN, AND \\ SUZANNE BRAGA
}

\begin{abstract}
Institute of Forensic Medicine, Lniversity of Berne, CH-3012 Berne, Switzerland /S.L.-G.]: Department of Pediatrics. Inselspital, University of Berne, CH-3010 Berne, Switzerland/S. B.J; Institute of Human Gene'tics. L'niversity of Freihurg. D-7800 Freihurg. Germany /G. W.J: and Neuropediatrics Unit. Department of Pediatrics. Lniversity of Freiburg. D-7800 Freiburg, Germany /L.-P.K.]
\end{abstract}

\begin{abstract}
The $\mathrm{X}$-linked recessive centronuclear/myotubular myopathy (XLR-CNM/MTM1), a severe neonatal disorder characterized by generalized hypotonia, muscle weakness, and primary asphyxia, has recently been mapped to Xq28. This report presents the first four prenatal diagnoses of XLR-CNM using DNA markers of the Xq28 region. The analyses of one female and three male fetuses revealed maternal transmission of the XLR-CNMassociated alleles in all four cases. Two of the male fetuses have been aborted, and the pregnancies of the third male and the female fetuses have been continued. The diagnosis of XLR-CNM at the birth of the third boy, as well as the pathologic findings in the muscle of one of the aborted fetuses, confirmed the linkage results of the prenatal analyses. Our findings prove the DNA markers St14, cpX67, DX13, and pSt35-691 to be useful in prenatal diagnosis of XLR-CNM and present the possibility to confirm the diagnosis by histologic examination of the first-trimester abortus. This permits an indirect prenatal diagnosis of XLR-CNM in chorionic villus biopsies at 9 to $12 \mathrm{wk}$ gestation, using DNA-based linkage analyses allowing early termination of an affected pregnancy. (Pediatr Res 33:201-204, 1993)
\end{abstract}

Abbreviations

$\mathrm{Fb}$, fibroblast

Mb, myoblast

RFLP, restriction fragment length polymorphism

XLR-CNM, X-linked recessive centronuclear myopathy

The XLR-CNM, well-described and documented by several authors (1-6), constitutes an entity on its own with severe hypotonia and respiratory failure. Affected boys usually die in the neonatal period. Muscles are characterized morphologically by hypotrophic muscle fibers with central nuclei surrounded by a clear perinuclear halo and destruction of myofibrils. In the prenatal period, spontaneous abortions of male fetuses, polyhydramnios, reduced fetal movements, and breech presentation can be observed.

No conclusive information concerning the carrier state can be expected from clinical examination or taking an electromyogram from asymptomatic family members. A number of obligate female carriers have been described to show abnormal muscle biopsies (5-9); however. Bucher et al. (3) and Keppen et al. (10)

Received November 28. 1991; accepted September 24. 1992

Correspondence: Dr. Sabina Liechti-Gallati. Institute of Forensic Medicine. University of Berne, Buehlstrasse 20, CH-3012 Berne. Switzerland. reported normal muscle histology in obligate carriers demonstrating the phenomenon of lyonization with a large variability of $\mathrm{X}$ chromosome inactivation in Mb-precursor cells. Thus, carrier detection by muscle biopsy is only reliable in cases with pathologic muscle histology, whereas carrier exclusion is not practicable in any case.

The gene for X-linked centronuclear myopathy was recently localized by linkage analysis to the chromosome region $\mathrm{Xq} 28$ (11-16). The determination of closely linked informative DNA markers as F8, p767, St 14, cpX67, and DX13 has resulted in improved carrier detection and has opened the possibility of firsttrimester prenatal diagnosis. Combination of physical mapping and linkage analysis data leads to the most probable marker order R/GCP-G6PD-(XLR-CNM-F8)-p767-St 14-cpX67-DX13, placing the XLR-CNM gene close to F8 (16).

We present here the results of four prenatal diagnoses in three XLR-CNM families by the use of RFLP.

\section{MATERIALS AND METHODS}

Families. In family 1 (Fig. 1A), two prenatal diagnoses have been performed at 9 and $10 \mathrm{wk}$ of gestation for an obligate carrier (03) having had two affected sons and one spontaneous abortion of a male fetus. In previous generations, nine males had died from asphyxia, proving an $\mathrm{X}$-linked pattern of inheritance.

The patient of family 2 (Fig. $1 B$ ) was the first child of a healthy unrelated couple with a negative family history of XLR-CNM. The mother's $(03)$ carrier state was not known, and she asked for prenatal diagnosis at $10 \mathrm{wk}$ of gestation. The pedigree of family 3 (Fig. IC) shows the patient to be a sporadic case, as in family 2 . His mother $(03)$ exhibits a slight muscle weakness, but the histopathologic evaluation of the muscle biopsy did not reveal any morphologic changes suspected of centronuclear myopathy.

Muscle biopsy was not available from the mother $(03)$ of family 2 to evaluate the carrier state.

Risk calculations. There is no information about gene frequency and mutation rate in XLR-CNM families. But in Xlinked recessive lethal diseases, in which no affected male has a chance to reproduce and, assuming equal mutation rates in eggs and sperm, the risk of a patient to be a sporadic case bearing a new mutation is thought to be one third (17). In the absence of any other information, a risk of one in three $(33 \%)$ would be given for a male fetus to be affected. Allowing for germline mosaicism, using the estimated recurrence risk B of $7 \%$ of DMD families (18), the risk of the fetus being affected would be $2 / 3 \times 1 / 2$ (carrier) $+\mathbf{B} \times 1 / 3$ (mosaic) (19). For the mothers in family 2 and 3 , the a priori recurrence risk has been calculated to be $36 \%$.

The obligate carrier in family 1 has an a priori risk of $50 \%$ for transmitting the XLR-CNM gene.

DNA analyses. DNA was extracted from peripheral-blood lymphocytes and from chorionic villi obtained from the at-risk 

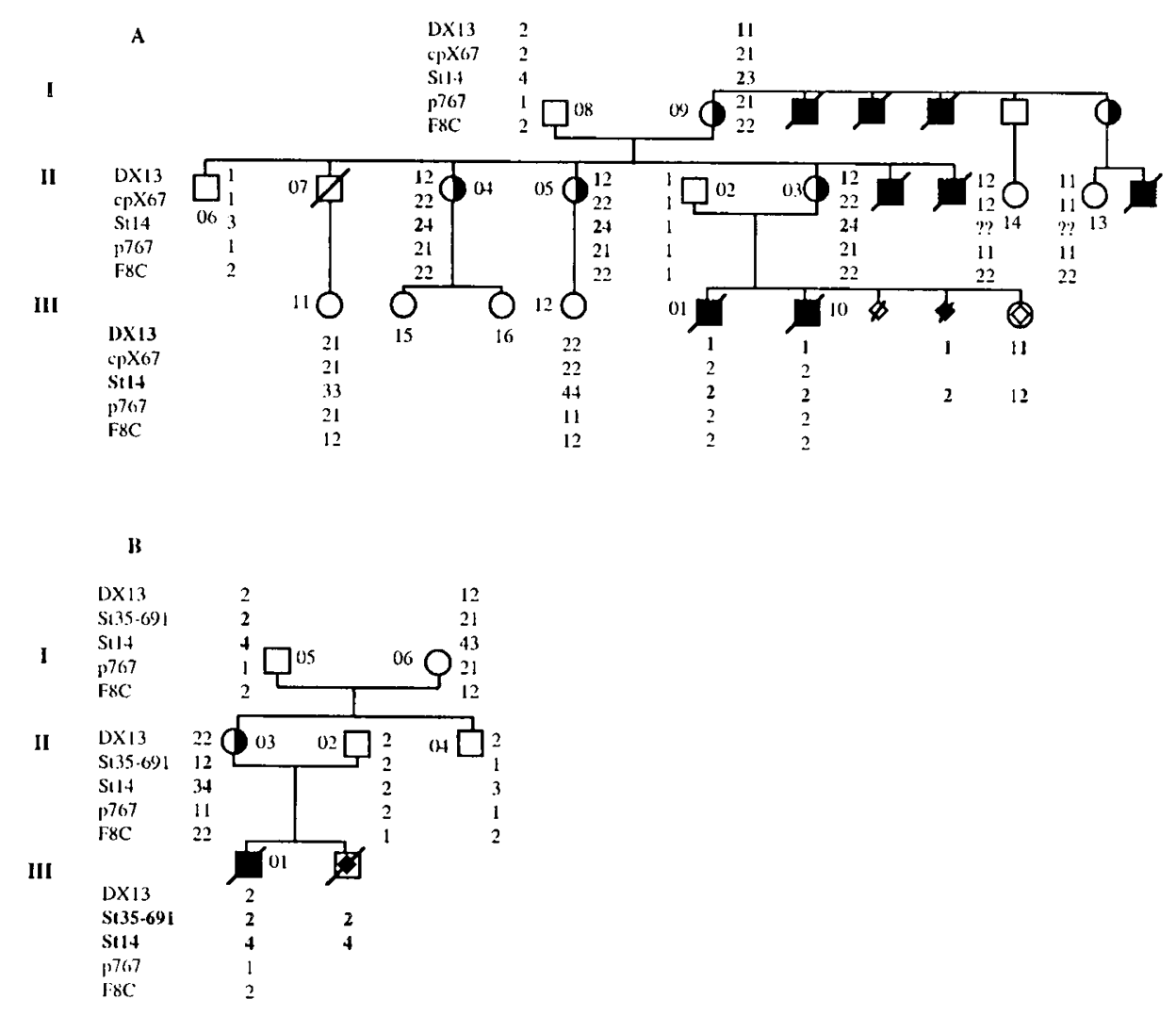

c

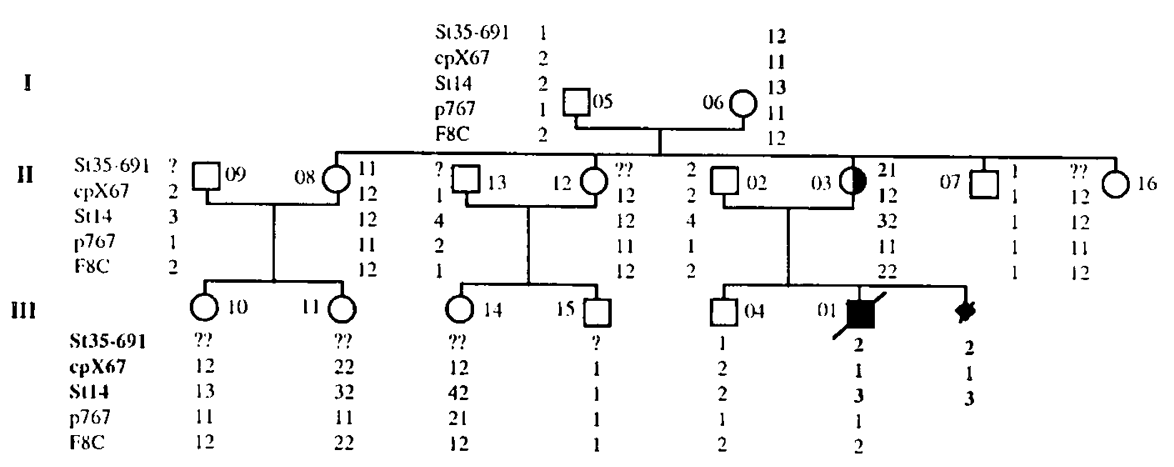

Fig. 1. Pedigrees and genotyping of three families with XLR-CNM using DNA markers from the Xq28 region. 1 and 2 indicate the larger and shorter alleles, respectively, of the RFLP. Bold type = markers used for prenatal diagnosis. $\boldsymbol{\square}$, Affected males: $\mathbf{O}$, carriers: $\diamond$, fetuses: $A$, family $1: B$. family 2: and C; family 3 .

fetuses using standard methods (20). Two and one half $\mu \mathrm{g}$ of DNA were digested with the appropriate restriction endonucleases (Boehringer, Mannheim, Germany) under the conditions suggested by the manufacturer. Southern blot analyses and probe hybridization were performed by previously described methods (21). The families had been typed before with the probes St14(DXS52), DX13(DXS15), pC(F8C), p767(DSX115), and

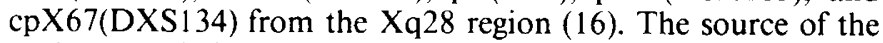
probes, restriction enzymes, allele sizes, and order of the loci have previously been described (16). The following probes were informative and used for prenatal diagnosis: St 14 and DX13 in family 1; St 14 plus an additional marker St35-691(DXS305) detecting RFLP with the restriction enzymes PstI (allele $15.1 \mathrm{~kb} /$ allele $22.9,2.2 \mathrm{~kb}$ ) and TaqI (allele $14.4 \mathrm{~kb} /$ allele $24.0 \mathrm{~kb}$ ) in family 2; and St 14, cpX67 and St35-691 in family 3 .

\section{RESULTS}

The first prenatal diagnosis performed in family 1 using the markers St 14 and DX13 demonstrated the XLR-CNM-associ- ated haplotype in the male fetus, indicating a high risk of being affected. The mother decided to terminate the pregnancy, which was done at $11 \mathrm{wk}$ of gestation, but unfortunately, no fetal tissue became available at pregnancy termination. The linkage analysis of the second prenatal diagnosis 10 mo later detected again the maternal XLR-CNM haplotype, but in a female fetus, predicting a healthy girl (Fig. 1A). In March 1990, the mother gave birth to her first unaffected child after five pregnancies.

In family 2 , the mother was informative for the two DNA markers St14 and St35-691. Prenatal diagnosis at $10 \mathrm{wk}$ of gestation showed the same marker-allele constellation in the male fetus as in the affected boy (Fig. $1 B$ ), increasing the risk of being affected to $38 \%$. The couple elected to continue the pregnancy, because the woman's carrier state was not defined. In December 1989 , the mother delivered an affected boy, who died $2 \mathrm{~d}$ after birth, proving her to be a carrier or a germline mosaic (with a probability of about $5 \%$ ). Tracing back the mutation origin in this family, we found the two patients carrying the haplotype of their grandfather.

Family 3 represents approximately the same situation as does 
family 2: one affected boy (isolated case), unknown carrier state of the mother, and a male fetus with the same grandmaternal XLR-CNM-linked haplotype as his deceased brother (Fig. 1C). The pregnancy was terminated at $13 \mathrm{wk}$ of gestation, and skeletal muscle of the fetus was analyzed by optical microscopy (semithin sections of Epon 812-embedded tissue; Fig. $2 a$ and $b$ ), histochemistry, and electron microscopy (Fig. 2c). The maturation state of the muscle corresponded to a fetal age of 13 wk (22). By histochemistry (ATPase, oxidative enzymes), there was a uniform enzyme reaction without a clear-cut subdivision into fiber types and no reciprocal reaction between oxidative enzymes on the one hand and ATPase on the other. Most of the cells detectable by electron microscopy were $\mathrm{Mb}$ as apparent single cells containing closely aggregated bundles of myofilaments forming z-bands or grouped with others in "early myotubes" surrounded by a basement membrane. $\mathrm{Fb}$ and other mesenchymal cells lacked

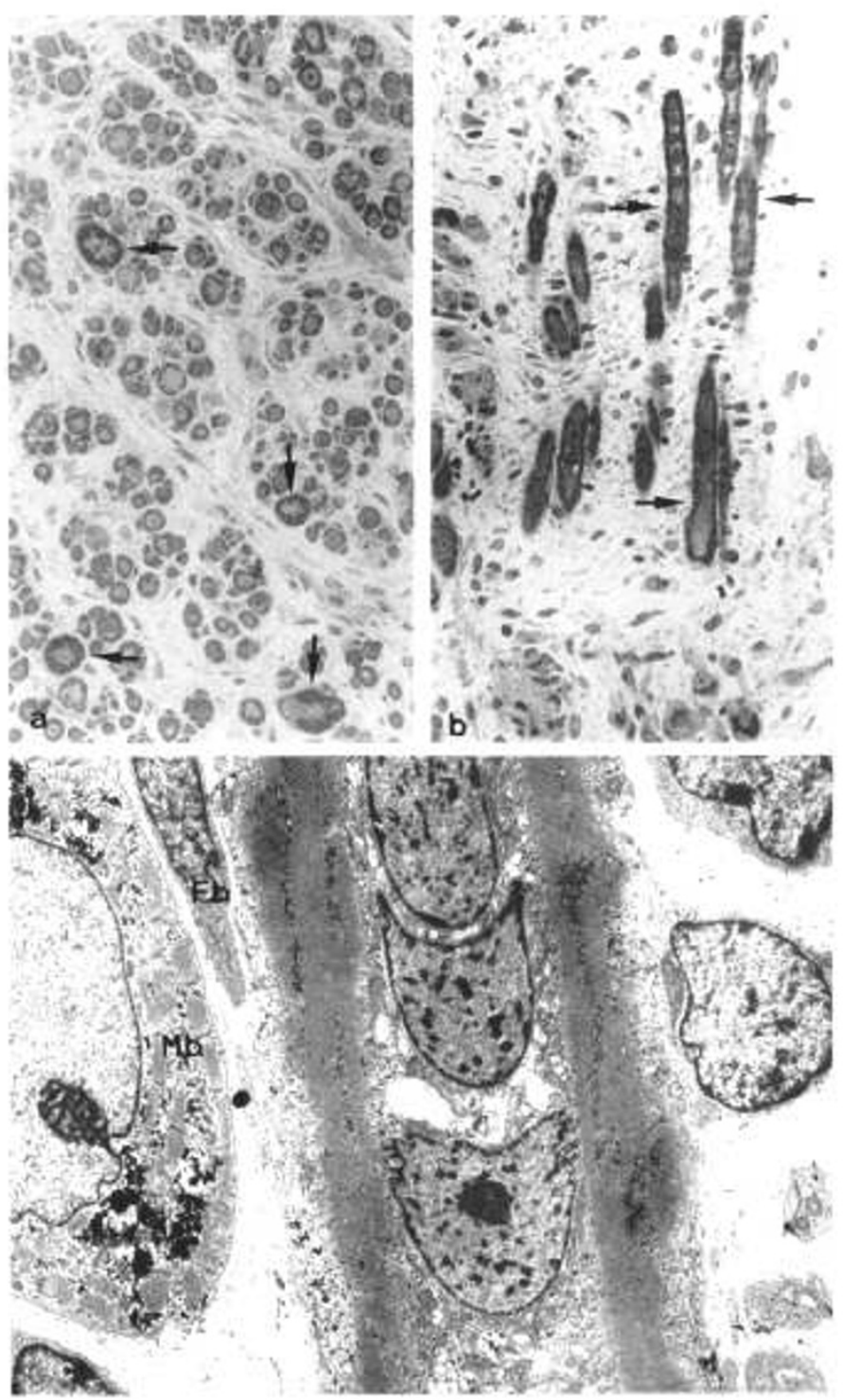

Fig. 2. Muscle sections of a 13-wk-old fetus at risk for X-linked centronuclear myopathy. $a$. Cross-section of skeletal muscle. Besides small. rounded $\mathrm{Mb}$ and mesenchymal cells. myotubes are visible $(\rightarrow)$. showing greater diameters and intensively stained homogeneous degencrated myofibrils in the periphery of the fibers. Staining: methylene blueazure. $\times 315 . b$. Longitudinal sections of myotubes $(\rightarrow)$ with centrally located nuclei and homogeneous degenerated myofibrils in the periphery of the fibers. Staining: methylene blue-azure, $\times 250$. c. Electron microscopic picture of a longitudinal section of a multinucleated myotube with homogeneous degenerated myofibrils. Staining: uranyl acetate and lead citrate, $\times 6100$. basement membrane and myofilaments and had extensive, welldeveloped rough endoplasmic reticulum and multiple elongated cytoplasmic extensions. However, multinucleated "later myotubes" were also identified, demonstrating a homogeneous destruction of their myofibrils (Fig. 2c). The central regions of these myotubes contain large nuclei with frequently prominent nucleoli, many mitochondria, glycogen particles, and sometimes "myelin figures," probably derived from degenerating mitochondria (Fig. 2c). In contrast to the general ultrastructural appearances of normal skeletal muscle from human fetuses of 10-14 wk gestational age, nearly no satellite cells (separated from the underlying myotube but enclosed by the same common basement membrane) were observed. These morphologic findings indicate the prenatal manifestation of the disease and lead to the interpretation of the mother being a carrier or a germline mosaic (probability $=5 \%)$.

\section{DISCUSSION}

Before the localization of the XLR-CNM gene and the availability of DNA markers linked to the disease, prenatal diagnosis had not been possible. We recently presented linkage analyses data of eight XLR-CNM families confirming close linkage of the XLR-CNM gene to the region Xq28 (16). We report here on the first four prenatal diagnoses of XLR-CNM using the recommended DNA markers of the $\mathrm{Xq} 28$ region. The analyses of one female and three male fetuses revealed maternal transmission of the XLR-CNM-associated alleles in all four cases, indicating a carrier state for the girl, an affected status for the boy of family 1 , and a risk of $38 \%$ to be affected for the fetuses of families 2 and 3. Two of the male fetuses have been aborted, and the pregnancies of the third male and the female fetuses have been continued. The diagnosis of XLR-CNM at the birth of the third boy, as well as the pathologic findings in the muscle of one of the aborted fetuses confirmed the linkage results of the prenatal analyses. Our findings prove the DNA markers St14, cpX67. DX 13, and pSt35-691 to be useful in prenatal diagnosis of XLRCNM and present the possibility of confirming the diagnosis by histologic examination of the first-trimester abortus. This means an important progress for the families at risk compared with the previous situation, where no prenatal diagnosis was available. However, the histologic analysis of fetal skeletal muscle does not present prenatal diagnosis itself, but enables checking of the DNA results. As long as one is using linkage-based indirect analyses, the counseling of families is more complex because one is dealing with probabilities of an affected or unaffected fetus, rather than with a definitive diagnosis based on direct observation, especially in families with sporadic cases. Prenatal diagnosis will not be possible in families in which the mother is uninformative or material of key persons is missing or when recombination events are found. Moreover, the probability of germinal mosaicism should be taken into account in calculation of carrier risks for females belonging to families with $\mathrm{X}$-linked recessive lethal diseases. That means a boy can be affected because his mother is a carrier or a germline mosaic, or because he is a new mutation.

St 14 and DX 13 showed highest linkage (lod-scores $=3.60$ and 2.02 ) at a genetic distance of $5 \%$ recombination, with the most probable marker order being XLR-CNM-St14-cpX67-DX13 (16). No recombination events were observed in the three families tested, leading to the estimated accuracy of the prediction of about $95 \%$. The use of flanking markers, not yet available for XLR-CNM, would significantly reduce the uncertainty of the counseling situation. Further analyses are under investigation to define closely linked flanking markers and to isolate the gene itself.

\section{REFERENCES}

1. Barth PG, Van Wijngarden GK. Bethlem J 1975 X-linked myotubular myopathy with fatal neonatal asphyxia. Neurology 25:531-536 
2. Van Wijngarden GK. Fleury P. Bethlem J. Meijer AEFH 1969 Familial "myotubular" myopathy. Neurology 19:901-908

3. Bucher HU. Boltshauser E, Briner J, Gnehm HE, Janzer RC 1986 Severe neonatal centronuclear (myotubular) myopathy: an X-linked recessive disorder. Helv Paediatr Acta 41:291-300

4. Donders G. Moerman P, Devlieger B, Spitz B, Van Assche FA 1987 X-linked centronuclear myopathy as a cause of floppy baby. Eur J Obstet Gynecol Reprod Biol 24:33-38

5. Oldfors A. Kyllerman M. Wahlström J, Darnfors C. Henriksson KG 1989 Xlinked myotubular myopathy: clinical and pathological findings in a family. Clin Genet 36:5-14

6. Braga SE, Gerber A, Meier C, Weiersmüller A, Zimmerman A, Herrmann U, Liechti-Gallati S, Moser H 1990 Severe neonatal asphyxia due to X-linked centronuclear myopathy. Eur J Pediatr 150:132-135

7. Ambler MW, Neave C, Tutschka BG, Peuschel SM, Orson JM, Singer DB 1984 X-linked recessive myotubular myopathy. I. Clinical and pathological findings in a family. Hum Pathol 15:566-574

8. Ambler MW, Neave C, Singer DB 1984b X-linked recessive myotubular myopathy. II. Muscle morphology and human myogenesis. Hum Pathol 15:1107-1120

9. Heckmatt JZ, Sewry CA. Hodes D, Dubowitz V 1985 Congenital centronuclear (myotubular) myopathy. A clinical pathological and genetic study in eight children. Brain 108:94!-964

10. Keppen LD, Hussian M, Woody B 1986 X-linked myotubular myopathy with intrafamilial variability and normal muscle biopsy in a definite female carrier. Am J Med Genet 25:723-724

11. Williams H, Sarfarazi M. Roberts K. Thomas NST, Cole G. Liechti-Gallati S Harper PS 1987 X-linked myotubular myopathy (XLMTM): another muscle disease gene localized to Xq28. Am J Hum Genet 41(suppl A): 110

12. Thomas NST, Williams H, Cole G, Roberts K, Clarke A, Liechti-Gallati S, Braga SE, Gerber A, Meier C, Moser H, Harper PS 1990 X-linked neonatal centronuclear/myotubular myopathy: evidence for linkage to Xq28 DNA marker loci. J Med Genet 27:284-287

13. Darnfors C. Larsson HEB. Oldfors A, Kyllerman M. Gustavson K-H. Bjursell G, Wahlström J 1990 X-linked myotubular myopathy: a linkage study. Clin Genet 37:335-340

14. Lehesjoki A-E, Sankila E-M. Miao J, Somer M, Salonen R. Rapola J, de la Chapelle A 1990 X-linked neonatal myotubular myopathy: one recombination detected with four polymorphic DNA markers from Xq28. J Med Genet 27:288-291

15. Starr J, Lamont M, Iselius L, Harvey J, Heckmatt J 1990 A linkage study of large pedigree with X-linked centronuclear myopathy. J Med Genet 27:281 283

16. Liechti-Gallati S, Müller B, Grimm T, Kress W, Müller C, Boltshauser E, Moser H, Braga S 1991 X-linked centronuclear myopathy: mapping the gene to $\mathrm{Xq} 28$. Neuromusc Dis 1:239-245

17. Haldane JBS 1935 The rate of spontaneous mutation of a human gene. J Genet 31:317-326

18. Bakker E, Veenema H, Den Dunnen JT, Van Broeckhoven C, Grootscholten PM, Bonten EJ, Van Ommen GJB, Pearson PL 1989 Germinal mosaicism increases the recurrence risk for new Duchenne muscular dystrophy mutations. J Med Genet 26:553-559

19. Grimm T, Müller B, Müller CR, Janka M 1990 Theoretical considerations on germline mosaicism in Duchenne muscular dystrophy. J Med Genet 27:683687

20. Kunkel LM, Smith KD, Bower SH. Borgaonkar DS, Wachtel SS, Miller OJ, Berg WR, Jones Jr HW. Rary JM 1977 Analysis of human Y-chromosome specific reiterated DNA in chromosome variants. Proc Natl Acad Sci USA 74:1245-1249

21. Liechti-Gallati S, Niederer BU, Schneider V, Mächler M, Alkan M, Malik N. Braga S, Moser H 1990 Haplotype analysis for CF-linked DNA polymorphisms in Switzerland. Clin Genet 37:442-449

22. Tomanek RJ, Colling-Saltin A-S 1977 Cytological differentiation of human fetal skeletal muscle. Am J Anat 149:227-246 